\title{
Multimodal Interaction Analysis: a Powerful Tool for Examining Plurilingual Students' Engagement in Science Practices
}

\section{Proposed Contribution to RISE Special Issue: Analyzing Science Classroom Discourse}

\author{
Sara E. D. Wilmes ${ }^{1}$ (D) $\cdot$ Christina Siry ${ }^{1}$ (D)
}

Accepted: 16 November 2020 / Published online: 4 January 2021

(C) The Author(s) 2021

\begin{abstract}
Science teaching and learning are discursive practices, yet analysis of these practices has frequently been grounded in theorizations that place language at the forefront of interaction and meaning-making. Such language-centric analytic approaches risk overlooking key embodied, enacted aspects of students' engagement in science practices. This manuscript presents a case of a plurilingual student's participation in science inquiry to demonstrate how multimodal interaction analysis can be used to examine the highly diverse array of communicative resources that she draws upon while participating in science, including gestures, facial expressions, vocal intonations, and languages. Grounded in dialogic theorizations of language, we first detail the multimodal interaction approach, and second, we show how multimodal interaction analysis beginning first with her embodied engagement, then coupled with her subsequent written and spoken engagement, reveals robust views of her engagement in science practices. Key to this methodological approach is multilayered analysis that backgrounds verbal or spoken communication to allow for an identification of embodied interaction resources employed. We emphasize how this analytical method allows us to conceptualize science as a practice that unfolds through and in interaction, as compared to a static body of concepts to be learned.
\end{abstract}

Keywords Multimodal interaction analysis $\cdot$ Primary science education $\cdot$ Dialogic $\cdot$ Multilingual contexts $\cdot$ Plurilingual students

Sara E. D. Wilmes

sara.wilmes@uni.lu

1 Institute for Teaching and Learning / Department of Education and Social Work/ Maison des Sciences Humaines, The University of Luxembourg, Belval Campus, 11, porte des Sciences,

L-4366 Esch-sur-Alzette, Luxembourg 


\section{Introduction}

Science is a discursive practice, one that has been examined by a wide body of science education research. The theoretical underpinnings of past studies investigating the discursive nature of science education have, more often than not, been grounded in theories that place language as the predominant feature of discourse. This foregrounding of language as an organizer of discourse and participation in science can disadvantage students who are engaged in doing science, yet who are working to master the language they are using to communicate. In our national context of Luxembourg, more than $50 \%$ of students in public primary schools are considered language learners and do not speak the languages of instruction at home (MENJE 2019). Although an embodied turn can be said to have taken place in sociocultural studies examining interaction in science classrooms, there exists a language bias in the field, or better put, a focus that prioritizes language as the starting point of interaction analysis in science classrooms. This language-centric view can serve to marginalize students who are not yet proficient in the languages of instruction and overlook opportunities to support the use of embodied non-linguistic modes to learn science (Williams and Tang 2020). Our aim with this article is to highlight multimodal interaction analysis (MIA) as a methodological approach that enables an illumination of the diverse array of communicative, interactional, social, and material resources students draw upon while engaging in science practices. Specifically, we build from the work of science education scholars who theorize interaction in classrooms as a situated, emergent, and contingent phenomena (e.g., Hwang \& Roth, 2011) to present a method of MIA grounded in dialogic theoretical positions (Bakhtin 1981, 1986) that can be used to analyze students' discursive, embodied engagement in science practices.

The goal of this manuscript is two-fold, in that it details illustrative episodes from the case of a plurilingual ${ }^{1}$ student in a multilingual classroom in our national context of Luxembourg to elaborate the specifics of a method of the MIA method that has emerged and developed in response to the high linguistic and cultural diversity in our national context in Luxembourg. Starting with the assumption that science education is an embodied practice that unfolds through interaction (Siry 2013), we present the methodology employed to construct a case of a plurilingual student named Calia as she participated in inquiry science. We will first elaborate the theoretical orientations that ground this research situated in dialogic theorizations of language, communication, and interaction (Bakhtin 1986; Roth 2009). Second, we elaborate the methodological underpinnings of the multimodal interaction analytical approach we use (Norris 2004; Wilmes and Siry 2020). Key to this methodological approach is multilayered analysis that backgrounds verbal or spoken communication to allow for an identification of resources employed in interaction that are not necessarily grounded in verbal interaction. Lastly, we detail the case of Calia's participation and engagement across multiple episodes of science inquiry drawn from a larger study investigating inquiry-based instructional approaches in primary schools in Luxembourg. The elaboration of focal episodes demonstrates how multimodal interaction analysis that begins with her embodied engagement in scientific practices first, then coupled with her written and spoken engagement next, reveals robust views of her engagement in science practices and her understandings. In particular, we will demonstrate how explicitly backgrounding the spoken and written aspects of her engagement in science practices

\footnotetext{
${ }^{1}$ We utilize the term plurilingual in our research, to refer to students who are learning science through a language they are also learning (Council of Europe 2018). Plurilingual allows for the valorization of all communicative resources one may draw upon, as compared to a view that standardizes language ability relative to a complete or whole, as is the case when using multi- or bi-. For an in depth discussion of this reason, see Wilmes et al. (2018).
} 
during analysis serves to highlight the embodied ways in which she engaged in science investigations.

\section{Theoretical Grounding and Literature Review}

The approach to analysis we present in this paper draws from theoretical perspectives grounded in the work of Bakhtin (Bakhtin 1981, 1986) and supports a dialogic view of human interaction in general, and interaction in classroom contexts in particular. Science teaching and learning are positioned as situated, culturally embedded phenomena, emerging and mediated in interaction through the resources that agents, in this case students and teachers, utilize as they participate in meaning-making events as elaborated next.

\section{Science as a Situated, Embodied Practice}

Through the sociocultural perspectives that ground this manuscript, science is conceived as a cultural enactment, as something done through contextualized action and interaction. We have written in previous work (Siry et al. 2012) that the act of "doing science" is an embodied, situated practice, one that emerges from participants' discourse-in-interaction. The use of "discourse" in this term is used to mean a diverse range of modes, or semiotic resources, that participants draw on as they make meaning, a process mediated by the resources utilized in interaction (Givry and Roth 2006; Kress 2010). These resources are interconnected and work together to mediate participants' embodied engagement in joint interaction. Research that explores the embodied nature of science learning and communication can create understandings of how learning and acting are connected, as well as create spaces for considering effective pedagogies that specifically build on the embodied nature of learning (e.g., Kontra et al. 2012; Otrel-Cass and Kristensen 2017).

\section{Dialogic Perspectives of Language and Communication-in-Situation}

In the early 1920s, literary philosopher Bakhtin wrote extensively about a reconceptualization of novels and texts, from what is today called a dialogic philosophical orientation. His writings, first published in Russian in the late 1970s, detailed new theorizations of written novels and texts, and presented a relational philosophical approach that positioned novels as relating simultaneously to multiple perspectives or voices. These voices, Bakhtin (1981) proposed, consisted of the voice of the reader, the voice of the author, and the "voice" of the novel in relation to the cultural perspective of the text. This shift, from a view of literature as stationary with static bodies of text, to dynamic culturally and historically situated pieces, proved to be a major shift that moved philosophical thought from formalism to more relational views (Bostad et al. 2004). This multi-voiced ontology moved theorizations from more formalist positions to those of interactionists, and similarly enabled a socio-political critique of the novel, to hold at its center an "epistemic focus on intersubjectivity" (Evensen 2004 p. 1). Bakhtin's theorizations were not directly elaborated relative to discourse and interaction, yet a diverse body of scholarly work since has drawn inspiration from the philosophy of dialogism and its associated ontology and epistemological positioning of dialog and discourse. Dialogism has proved to be a useful theoretical lens to examine language and voice in cultural contexts in general (Shields 2007), and in science education contexts in particular (e.g., Pappas et al. 2002; Roth 2009). 
It is particularly useful to consider the conceptualization of language that can be drawn from Bakhtin's work when considering interaction in science classrooms. The Dialogic Imagination (1981) is a book of translations of his texts, from Russian into English, wherein Bakhtin elaborated language as "any communication system employing signs that are ordered in a particular manner" (as described by Lotman 1977, p. 8). In his earlier, more philosophical writings, Bakhtin elaborated a social conceptualization of language as consisting of, "a discourse peculiar to a specific stratum of society (professional, age group, etc.) within a given social system at a given time" (p. 430). He went on to further describe the relationship to the multiple voices within a text as heteroglossic. This dialogic conceptualization of discourse as having meaning in interaction and being socially rooted provided a view of language as mediated by the interactions of social actors and as communication-in-situation.

The dialogic view of communication-in-situation is further elaborated through several characteristics that are key to its use as a theoretical basis for MIA, namely its relational view of dialog and an embodied view of language. These theorizations enable a particular lens on dialog, one which we have elaborated into a methodology to guide analysis of classroom interaction. In order to build an understanding of this particular methodological approach, the next sections elaborate the central features of the MIA approach as grounded in dialogism, and its applicability to a theoretical application for MIA in general, and in science education contexts in particular.

\section{Dialogism as a Relational Perspective}

Dialogism is an epistemological approach that is relational, and built on an understanding of the mutuality of differences. Language mediates relations. For Bakhtin, the most irreducible unit of language is the utterance, which forms the basis of interaction. Every utterance generated is always different, through space and time, and it is dialog that holds together these differences in a relational, interactive process (Holquist 2004). Positioning dialog through the perspective of the interaction "between mind and world" (Holquist 2004, p. 4) acknowledges a multiplicity of perspectives inherent in the utterance and in social life and human interaction. Through these groundings, words have dynamic determinations. They come from the speaker and at the same time are directed towards someone else. The meaning of a word, then, arises from both the speaker as well as from the listener, and resides within the context in which the dialog is taking place. Reality, in this view, is an emergent collection of relations that are situated within the larger socio-political nature of the word and its users (Rule 2011, p.924). Such a relational perspective theorizes that signs are mobilized in communication through language. Several science education researchers have recently drawn upon Bakhtin's dialogic perspectives in the analysis of interactions in multilingual contexts to demonstrate, for example, that authoritarian discourses dominate teachers' language choice in interactions with students in multilingual classrooms (Salloum and BouJaoude 2019).

Bakhtin's works focused on language and text, and as such, language was positioned as the most important sign in communication. This view of language as the predominant organizer of social interaction has dominated much of classroom research, in particular with students who are learning science in languages they are also working to learn. Our work seeks to overcome the bias inherent in langauge-centric approaches by building a methodology that brings the dialogic notion of the embodied utterance to the forefront, as is necessitated when working towards equitable opportunities for students who are learning science in a language they are also working to master. 


\section{Dialogism as Embodied}

Bakhtinian perspectives to this research allow us to analyze "interaction-in-situation" in which the body is the locus of experience (Roth 2009, p. 125). "In this dialogue a person participates wholly and throughout his whole life with his eyes, lips, hands, spirit, with his whole body and deeds" (Bakhtin 1984, p.293). The role of the whole body for learning is not to be underestimated. Knowledge is connected to the body, and as such, the concepts that are processed in the mind must be connected to "the world that the body inhabits" as the body mediates our thinking, our being, and thus our ways of learning science (Roth 2009, p. 218). Grounded in dialectical understandings of social life, our theoretical perspectives position the doing of science and the talking of science as dialectically related and inseparable. That is, these constructs are each part of the same whole; each impacts the other, and both are critical as students enact science as practice. Acknowledging this relationship necessitates methodological approaches that do not prioritize either the spoken or the done aspects of science, but instead prioritize both together. With this understanding grounding the research we undertake, we draw on multimodal analysis of embodied participation in the practices of science (e.g., Hwang and Roth 2011a, b) to examine a plurilingual student's engagement in science in a multilingual classroom and explore how foregrounding and backgrounding different forms of engagement highlight the diverse resources students bring to science. Dialogic theoretical perspectives are ripe with possibility for critical views of the study of discourse in science education and, when coupled with embodied theorizations, present opportunities to examine the embodied participation of students in the practices of science. The sections that follow elaborate how this multimodal interaction analysis approach reveals key details about participation in science, especially important for students who may be marginalized by analytical lenses that prioritize language as the primary means to participation.

\section{Multimodal Views of Science Classrooms}

Researchers have been calling attention to the particularly multimodal nature of science as a discipline for more than two decades (e.g., Lemke 2004), highlighting how this multimodal nature is reflected in aspects of science classrooms (e.g., Kress et al. 2001). A growing body of research has drawn upon multimodal perspectives of science classrooms and explored how students and teachers utilize semiotic resources in ways that are locally contextualized and that unfold through interaction (e.g., Márquez et al. 2006; Varelas and Pappas 2013; Williams et al. 2019). Lemke (2004) proposed the term "semiotic hybrid" to convey the idea that scientific concepts are simultaneously verbal, visual, mathematical, and actional. This can be seen, for example, as a teacher explains science concepts to a class and employs multiple modes simultaneouslygesture, body position relative to the class, and speech - to explain its use (e.g., Moro et al. 2019). Multimodal methodologies have increasingly been used to examine the semiotic processes employed in science education with students who are learning science through languages they are also working to learn (e.g., Zhang 2016). In their study, grounded in social semiotic discourse analysis, Williams et al. (2019) employed multimodal analysis to examine bilingual students' participation in science practices. Through analysis of the modal complexes students employed at different stages of science inquiry, it was shown that multimodal instruction incorporating opportunities for speaking, drawing, and writing afforded students multiple pathways for interaction and communication through the self-selection of modal ensembles (Kress 2010), and thus were able to participate in science inquiry regardless of their language abilities (Williams et al. 2019). 
Relatedly, a recent study from our team similarly draws upon sociocultural theoretical perspectives coupled with multimodal methodologies (Siry and Gorges 2019), as the authors present the case of how a plurilingual student in an early-childhood classroom made her understandings about the phenomena of sound evident through multimodal explanations that included drawings, gestures, expressions, sounds, and words. This analysis revealed the nuances of her communication-in-situation and a wide range of resources that mediated her explanations, as well as the role of open-ended dialogic structures for mediating the processes of meaning-making. This work underscores the power of a multimodal analytical focus that centers embodied and material semiotic resource use along with the spoken and written, in that an analytical focus on simply the spoken or written overlooks embodied participation in science practices. It is this necessity that also guides the research we present here.

\section{Multimodal Interaction Analysis}

Over the past 10 years, the number of studies drawing upon multimodal analytical approaches to examine science teaching and learning has risen exponentially (Williams and Tang 2020). Within this scholarly body of work, researchers have utilized multimodal analytical frames that draw from various theoretical underpinnings, and differ across several factors, including, how modes are theorized, the role of objects and artifacts relative to analysis, and how sociocultural and historical aspects of analysis are considered (Jewitt et al. 2016; Pirini et al. 2018). The methodology presented herein is grounded in multimodal interaction analysis (MIA) (Norris 2004, 2012; Norris and Pirini 2017), which takes a holistic approach to analysis grounded in the perspective of the mediated interaction (Wertsch 1998), with the unit of analysis being individual actions (Pirini et al. 2018). As our research is grounded in the embodied perspectives introduced above, we take a more micro-interactional view than prior uses of MIA. This allows us to examine the diverse modal complexes employed by actors through interaction in the context of science instruction. The sections that follow present excerpts selected from the case study of Calia, a plurilingual student, to illustrate the process of MIA grounded in dialogical theorizations of communication (Bakhtin 1986). This approach draws from the work of Norris $(2004,2020)$ and honors the agentic employment of modal ensembles in interaction within socially contextualized events. The MIA analytical approach allows for the examination of research questions such as, which modes and sign complexes do students and teachers employ as they engage in science? And what embodied actions or modes contribute to this participation? These questions remain central through the analytic process and become critical for the emergence of implications through the process of interpretation.

In the sections to come, we will elaborate the methodological underpinnings of the MIA approach and, with the above questions as central, we will detail the case of Calia and her participation across multiple episodes of science inquiry in a primary classroom in Luxembourg. The elaboration of Calia's case, through MIA, will demonstrate how multimodal analysis that begins with embodied engagement in scientific practices first, then coupled with her written and spoken engagement next, reveals robust views of her engagement in science practices and her understandings. In particular, we will demonstrate how explicitly backgrounding the spoken and written aspects of her engagement in science practices during analysis serves to highlight the embodied ways in which she engaged in science investigations. 


\section{The Context for Our Work}

\section{Science with and for Multilingual Students: Super-diverse Primary School Contexts}

The present study was conducted in Luxembourg, a linguistically and culturally diverse European country with a national multilingual school policy, which mandates that students are instructed in three languages in primary school (French, German, and Luxembourgish). Students are expected to be proficient in all three languages upon the completion of primary school. Adding to the linguistic complexity within such a trilingual system, it is common that children speak a language other than one of the languages of instruction at home and in out-ofschool contexts. Although international science education policies for elementary school are shifting to hold an increased focus on engaging students in science practices (e.g., NRC 2012), many educational policy and reform documents emphasize the spoken and written aspects of science, as is illustrated by statements such as "engagement in practices is language intensive and requires students to participate in classroom science discourse" (NGG Lead States 2013, Appendix D, p.9). This language-intensive focus on engagement in science practices in policy documents can position culturally and linguistically diverse (CLD) students at a disadvantage. As the students we work with have varying degrees of fluency in the languages of instruction, we have sought to develop research approaches that afford lenses on the varying and diverse resources these children draw on as they make meaning around their science investigations.

\section{The Research Project and Multilingual Classroom Context}

The intention for this manuscript is to present a methodological argument for the use of MIA with CLD students. Toward this end, we will next elaborate and unpack the methodology through the use of data excerpts. The analysis presented here is a subset of a larger research project $^{2}$ through which we examined the integration of student-directed science inquiry and language learning in primary schools. At the focus of the study was science instruction that arose from students' questions and self-designed investigations which sought to position students to draw on their diverse perspectives as learning resources. The overarching goal was to examine the implementation of student-directed inquiry science instruction and to analyze interactions during students' inquiry investigations. The analysis presented here arises from one participating classroom, a fourth-grade class of plurilingual 10-11-year-old students in an urban primary school in Luxembourg City.

The 16 student participants were ethnically, social-economically, and linguistically diverse, and primarily use Luxembourgish in their daily interactions with their teacher, one of the three school languages (the others being French and German). Despite the national trilingual school policy, school subjects are typically taught monolingually, with science, for example, to be taught through German (Plan d'Études, MENJE 2011). This is a crucial contextual feature in our work because of the complex linguistic landscape it creates for children whose first languages are not Luxembourgish nor German. Given that Luxembourg has an immigration rate of approximately $50 \%$ and a trilingual education system, more than half of children study in classrooms where the language(s) of instruction is not their first language (MENJE 2019). This linguistic environment serves as a key factor in illuminating the claims we make, as it is this linguistic diversity that prompted us to investigate modes of analysis that account for the

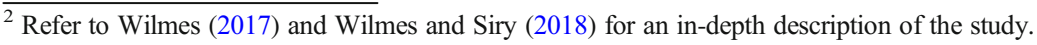


communicative complexities of these classrooms, in order to work towards seeing the full spectrum of strategies - not just linguistic - employed when students engage in the processes of science and inquiry. Of the 16 students we worked with in the classroom, all were plurilingual in a range of languages, not just the three national languages. This complex classroom linguistic environment is representative of classrooms nationwide navigated on a daily basis with different degress of success by both students and teachers.

The multilayered data corpus collected consisted of approximately $40 \mathrm{~h}$ of whole-class and small-group digital video recordings, supported by student classroom artifacts from inquiry sessions that took place over a 3-week instructional period and supplemented by audio recordings of research team debriefings conducted after each teaching session. Student science notebooks were used by students to record students' questions and investigations. ${ }^{3}$ Studentfocus group interviews were conducted to capture students' impressions and details regarding students' linguistic repertoires. This provided insight into students' relationships to the numerous national languages and was key to helping us to understand students' language choices and conversation patterns as we analyzed the data. Additionally, we co-taught with the classroom teacher, which provided us with additional perspectives on the unfolding of events in this classroom as we worked at the elbow (Roth and Tobin 2004) of the teacher, and each other, in orchestrating science instruction. All data sources were analyzed in their original version. Translation into English was conducted by plurilingual members of our research team for presentation and publication reasons only.

\section{Multimodal Interaction Analysis: Elaborating the Method}

Next we elaborate the method of MIA used to examine students' and teachers' communication-in-situation with the aim of elucidating aspects of students' participation in science practices. We engage in several steps that serve to narrow and deepen our focus on students' multimodal interactions, as we start with the overall classroom and instructional context and then refine the analytic view onto a focal case. Analysis of the semiotic resources employed in interaction, and that mediate communication and understanding, are then analyzed over the timeframe of interactions.

MIA is undertaken through a series of four interrelated steps that, when conducted in a recursive, iterative fashion, afford insight into the mobilization of modes within interactions over the course of science instruction. The four steps are (i) rich description of science instructional context, (ii) video viewing with the sound off, (iii) selection of the analytical focus, and (iv) layering on verbal communication (Fig. 1). We next elaborate each step followed by the presentation of select episodes constructed using the method presented.

Rich Description of the Instructional Context The first phase of analysis is the construction of a detailed overview of the instructional context relative to the emergent research focus in the form of an analytic log (Fig. 1, left). The overview chronologically details events as they unfolded in real time during science instruction as reconstructed from a review of our researchers' field notes, our coteaching experiences, and our recorded teaching reflections. Beginning with such an analytic log allows an overall view of the social organization the

\footnotetext{
$\overline{{ }^{3} \text { Refer to authors Wilmes and Siry }}$ (2020) for detailed elaboration of the use of science notebooks in this study.
} 


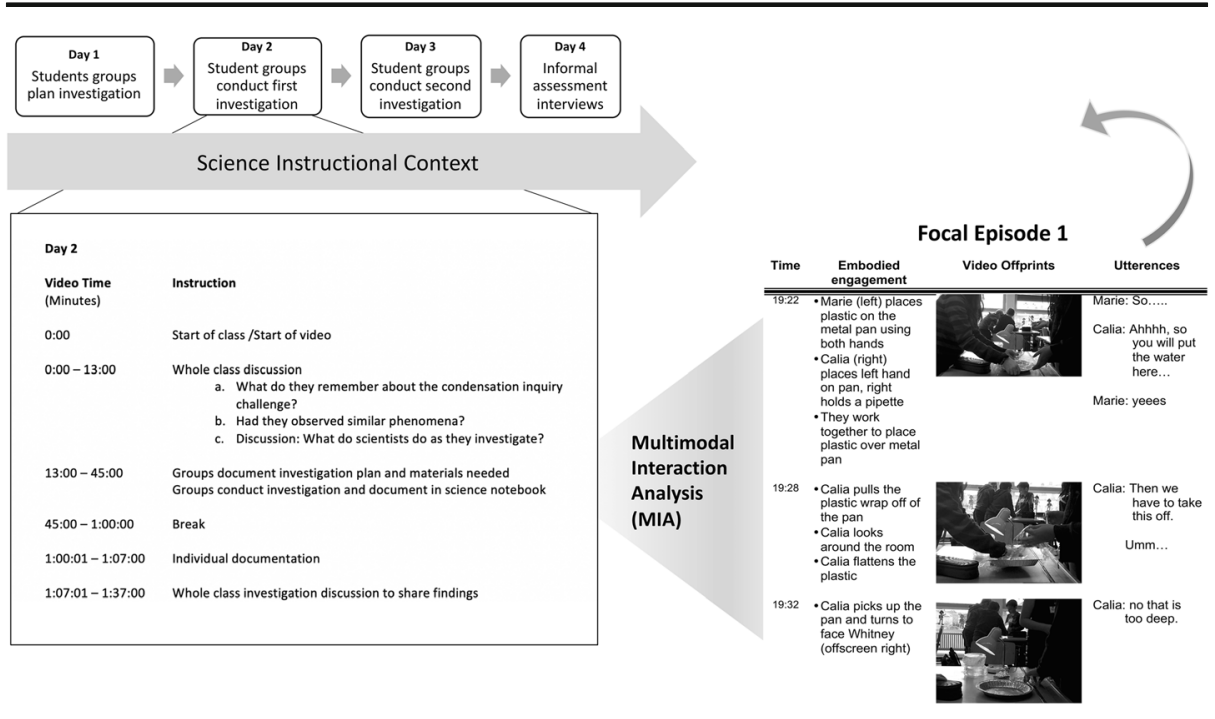

Fig. 1 Multimodal interaction analysis (MIA) overview. An analytic log (left) is constructed to detail the instructional context and interactions relative to science instruction. Multimodal transcripts (right) are then constructed during video analysis

students were directed to use by the teachers coupled with a summary of the instructional steps undertaken.

Video Viewing with the Sound Off The next analytical phase involves watching the entire corpus of video at a faster speed with the sound turned off. This allows for detailed observation of the embodied engagement of students and teachers as it unfolds in interaction. During this viewing, multimodal transcripts (Erickson 2017) are constructed that note key social and material engagements (Fig. 1, right). Analysis during this second stage involves documenting modes (gestures, gaze, material interaction) employed in interaction and thus viewing, and reviewing the videos multiple times, both sped up and in real time, again with the sound off. This reveals insights into the resources employed in interaction by students and teachers within aspects of instruction and relative to their engagement in science practices. Grounded in a dialogic perspective, first viewing the video with the sound off allows the researcher to break from a language-oriented view of interaction and to draw analytical focus attention to the embodied aspects of interaction as all modes associated with sound are not perceived during this phase of analysis. From this second phase, a focus for analysis emerges.

Selection of the Analytic Focus During this subsequent stage, possible foci for analysis emerge. These may be relative to a particular student, particular forms of interaction between students, or types of interactions between students and teachers. We have described in detail elsewhere how this approach guided analysis of three focal groups of plurilingual students (Wilmes and Siry 2020), as well as how it enabled an understanding of how a plurilingual student moved from not verbally participating in group science discussion to active verbal participation (Wilmes and Siry 2018). 
Layering on Verbal Communication The next layer of analysis involves viewing the video corpus, but with an analytical focus attuned to the verbal utterances and connections to multimodal interactions detailed in phases 1 through 3. During this phase of analysis, utterances are layered onto the multimodal transcripts (Fig. 1, bottom right; Fig. 2). It is important to note that while verbal communication is layered on during this fourth phase of analysis, given the theoretical positioning we draw from regarding the employment of modes in modal complexes as signs (Kress 2010), utterances are not considered to be of a different value. The reasoning for separating them in analysis is to purposely offset the use of verbal utterance as the organizing principle for analysis of classroom interaction.

Steps 2 and 4 (viewing with the sound off/layering on verbal communication) typically are conducted over multiple rounds of viewing over the analytic process, as this helps to refine and narrow the focus onto the relationship between the different modes and what is occurring in interactions. This allows for an analysis aligned with our theoretical grounding that considers the dialectic relationship between talking science and doing science (Roth 2005). With this overall elaboration of the phases in the multimodal interaction analytical approach, the sections that follow present episodes extracted from the case of Calia, to illustrate the use of MIA, especially as relevant for plurilingual students and multilingual classroom contexts.

\begin{tabular}{|c|c|c|c|}
\hline Time & $\begin{array}{c}\text { Embodied } \\
\text { engagement }\end{array}$ & Video Offprints & Utterences \\
\hline$\overline{19: 22}$ & $\begin{array}{l}\text { - Marie (left) places } \\
\text { plastic on the } \\
\text { metal pan using } \\
\text { both hands } \\
\text { - Calia (right) } \\
\text { places left hand } \\
\text { on pan, right } \\
\text { holds a pipette } \\
\text { - They work } \\
\text { together to place } \\
\text { plastic over metal } \\
\text { pan }\end{array}$ & & $\begin{array}{l}\text { Marie: So..... } \\
\text { Calia: Ahhhh, so } \\
\text { you will put } \\
\text { the water } \\
\text { here... } \\
\text { Marie: yeees }\end{array}$ \\
\hline $19: 28$ & $\begin{array}{l}\text { - Calia pulls the } \\
\text { plastic wrap off of } \\
\text { the pan } \\
\text { - Calia looks } \\
\text { around the room } \\
\text { - Calia flattens the } \\
\text { plastic }\end{array}$ & & $\begin{array}{l}\text { Calia: Then we } \\
\text { have to take } \\
\text { this off. } \\
\text { Umm... }\end{array}$ \\
\hline 19:32 & $\begin{array}{l}\text { - Calia picks up the } \\
\text { pan and turns to } \\
\text { face Whitney } \\
\text { (offscreen right) }\end{array}$ & & $\begin{array}{c}\text { Calia: no that is } \\
\text { too deep. }\end{array}$ \\
\hline
\end{tabular}

Fig. 2 Multimodal transcript excerpt. The transcripts are built by first documenting embodied interactions over time (left) and then layering on verbal utterances (right) 


\section{Multimodal Interaction Analysis of Calia's Engagement in Science Investigations}

To illustrate the MIA approach, we present components of the analytic process used to develop Calia's case. Calia was selected as a focal case for three reasons. First, she demonstrated a high level of engagement in the student-designed science investigations. Second, the nature of her engagement changed relative to the social organization of the classroom (the language being used, the instructional format), and third the high level of complexity of her linguistic repertoire. Our initial interest in Calia emerged from classroom observations of her interactions and analysis of student interviews during which she shared information about her linguistic repertoire and her thoughts about science instruction during primary school in general, and within the context of this project specifically. At the time of this study, Calia was 10 years old, and it was her second year in a Luxembourg public primary school. Prior to this, she had lived and attended school in France. When interviewed about the languages she speaks at home, Calia explained:

I, I, at home sometimes I sometimes speak (Luxembourgish) with my mother, but my mother doesn't know Luxembourgish so well. I speak a little Luxembourgish with her, a little French, Portuguese, and Cape Verdean. And with my father (I speak) French, and Cape Verdean, and with my brother German, Luxembourgish, French, Portuguese, and Cape Verdean. (Calia, Student Interview 20140213, translated from German)

Calia and the members of her family possess diverse linguistic repertoires, which is common for the majority of primary students in our national context. In working with Calia and her class, and observing her interactions with her classmates, we came to see that she was most expressive and seemed most comfortable speaking in Luxembourgish during small-group interactions and with peers. We noted that when she was speaking with students who have a stronger proficiency in French than Luxembourgish, she seamlessly switched from Luxembourgish to French, and back again. In contrast, when speaking in German, which she only required for speaking with teachers, her speech typically carried markers of someone communicating in a language in which they are not confident, such as the insertion of a repetitious "I" in her quote above. This repetition serves as a placeholder and was often heard when Calia spoke German, but was not evident when she spoke Luxembourgish. Once Calia was selected as the focus, we began multimodal analysis of her moment-by-moment interactions across the science unit. Through an elaboration of Calia's participation, we aim to show how MIA provides micro-level insight into her moment-to-moment use and employment of semiotic resources during her situational engagement in student-directed science investigations. Iterative rounds of analysis examined Calia's moment-to-moment communication-insituation and revealed the embodied multimodal resources she engaged and drew upon in designing investigations to explore condensation and evaporation over multiple days of inquiry investigations (Fig. 1). Three illustrative episodes are next presented to demonstrate how Calia differentially employed communicative modes in interaction. These episodes are presented to illustrate three points that would have likely been overlooked if analysis had been framed by verbal utterances. These episodes will show first, Calia's interaction with materials; second, her written science investigations; and third, her explanation grounded in gestures of the phenomena she observed. Our intent with these three excerpts is to demonstrate how multimodal interaction analysis grounded in dialogic perspectives brings to the foreground 
events and embedded aspects of these events that would have not been foregrounded with a verbal framing of interaction.

Episode 1: Engaging with Science Investigation Tools On day 1 of the condensation and evaporation inquiry unit, students were first engaged with the unit topic through an inquiry challenge story, which described a situation of two students sleeping in a tent (Konicek-Moran 2008). Through the night, one student in the story wakes as drops are falling on her from the inside surface of the tent. After reading the story, students were asked to discuss their ideas, share their ideas with the class, and subsequently design investigations to explore how the condensation might have formed inside the closed tent. Calia read the text in German, and then discussed her ideas with her partner in Luxembourgish.

Calia was then asked to sit with a partner, and student pairs were provided with a tray of materials they could use to start their investigation planning. Without speaking to her partner, Calia interacts with the materials before her on the table. Calia picks up the thermometer and gazes at the thermometer (Fig. 3a). With her gaze fixed on the thermometer, she places her hand over the thermometer's glass bulb (Fig. 3b), then she releases her hand. She then repeats this action, wrapping her hand around the bulb, releasing, wrapping her hand around the bulb, releasing, with her gaze oriented toward the base of the thermometer.

Calia's engagement with the thermometer provides insight into her initial engagement with the materials that she later incorporates into the multiple science investigations she designs to investigate the condensation. In other words, through a multimodal embodied view of her actions, this moment underscores the benefits of this methodological approach, as it shows how Calia's multimodal and embodied engagement was enacted without the production of verbal exchanges. If we had decided to frame her interaction during this phase of inquiry through verbal exchanges, the initial handling of the thermometer and exploring how it works would not have been foregrounded.

Moments after Calia interacts with the thermometer, she speaks to her partner in Luxembourgish saying, Oh...Se geet net, Oh...that (the thermometer)...it does not work. He responds, Doch et geet, Yes, it works, grabbing the thermometer from her (Fig. 4a), and saying Du musst immer an décke kale Wassser... huerno geet denn erof, You must always in very cold water... then it goes down, as they both gaze down at the thermometer as he wraps his hand around the bulb at the bottom (Fig. 4b). The verbal interaction around whether or not
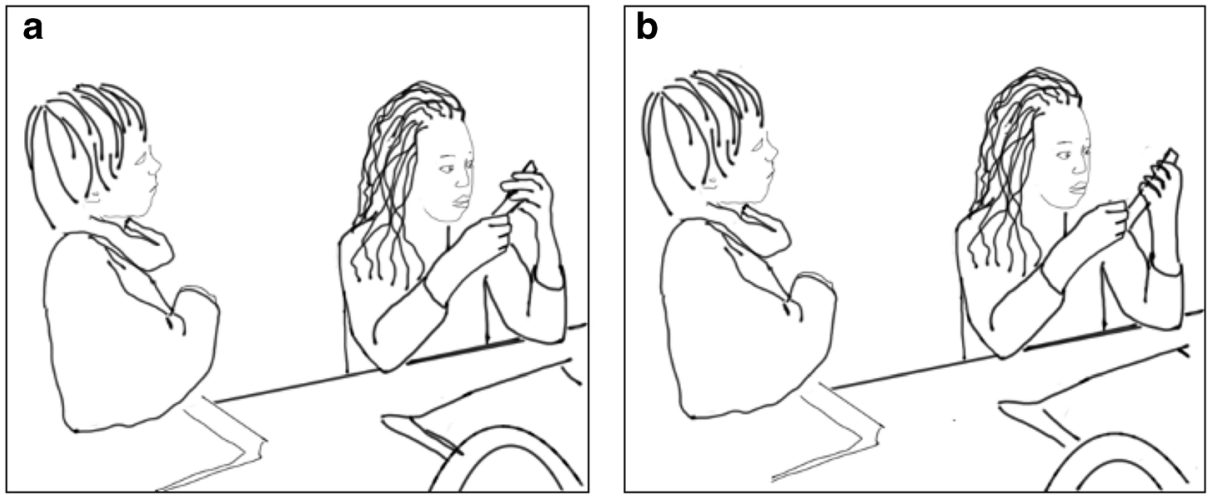

Fig. 3 Calia examines the thermometer, a key tool in her later investigations 

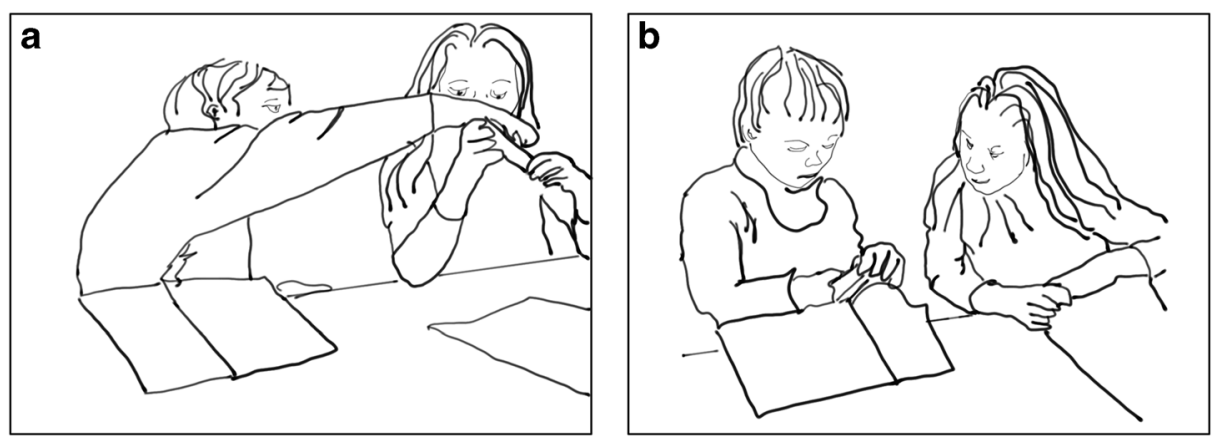

Fig. 4 Calia and her groupmate discuss the thermometer

the thermometer works serves to further establish her interaction with the materials and with her partner, and situates her later investigations which incorporate the thermometer.

Episode 2: Calia Designs Four Investigations The second episode we detail took place later on day 1 of the inquiry science unit as students conducted student-designed investigations to explore condensation phenomena. Calia was next observed sitting with three of her classmates at a group desk. The teachers had instructed students to form student groups and begin to conduct their first investigation. Calia could be seen sitting with the group, but leaning over to the side, her gaze fixed on her notebook (Fig. 5a). She remained in this focused position, writing in her science notebook, for a period of $10 \mathrm{~min}$ while her three groupmates worked to set up equipment for a first investigation (Fig. 5b). During this time, Calia constructed four notebook entries in her science notebook (Fig. 6). The four plans, written in German, each detail materials she proposed using (a cup, a plate, a petri dish) and the steps she would undertake. The four investigations are similar in that they all incorporate warm water, but with varying materials. As she focused on writing the multiple investigation plans, her three group members could be heard discussing a light source, the containers they would use, and making sure the light worked. Calia did not participate verbally in this group work. She remained by herself in the interactional space of her notebook (Wilmes and Siry 2020) and developed the four investigation plans. Once Calia completed these entries, she says in German to a teacher passing by, Ich habe zehn geschrieben, I wrote ten (pages in her notebook), closes her notebook, and turns to her group mates and joins them in setting up the investigation equipment saying to them in Luxembourgish, Waat mëss du? What are you doing? In this episode, multimodal interaction analysis illuminated the complexities of her engagement with
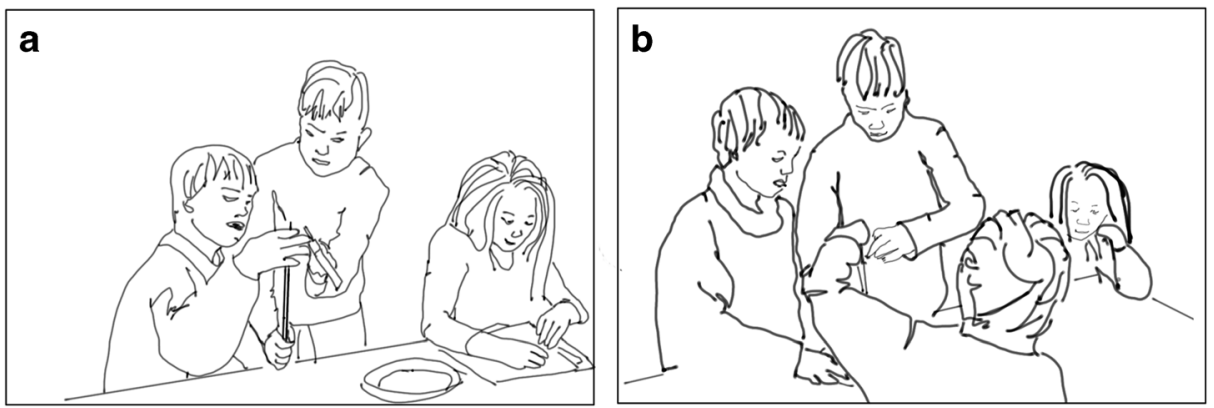

Fig. 5 Calia sits apart while her group sets up condensation investigation equipment and writes 
semiotic resources across languages, modes, and interactional spaces in that she was writing in German in the personal space of her notebook, yet interacting with group mates in Luxembourgish.

Episode 3: Calia Explains Her Understandings to a Teacher In this third illustrative episode, Chris, the second author, asked Calia on day 4 of the investigations to explain the understandings she had regarding the development of condensation. Until this point, Calia and her group members had conducted several investigations of the formation of condensation on different containers with different plastic coverings. During one of the investigations on day 3 , they placed a plastic bag over a warm water of beaker and were observed making a concave surface with their fingers to push the bag into the beaker (Fig. 7). Moments later, Chris approached their group and crouched down at their table to speak with the group. Calia began to speak, and as she did, she could then be seen making several gestures using the cover of her notebook (Fig. 8). The gestures she makes with her notebook caught our attention during analysis in that they are very similar to the setup of a prior investigation in which condensation formed on an indented sheet of plastic covering a glass container of warm water.

Chris began by saying to Calia in German, Erklär was deine Meinung nach passiert ist. Wie kannst du versuchen zu erklären, was du erforschst hast? Explain what you think happened. How can you attempt to explain what you explored? Calia gazed at her notebook on the table in front of her as she started her explanation and began to motion using her two hands and the cover of her notebook (Fig. 8). Calia explains in German, also ahhh ... zum Beispiel, wenn Sie ... Wasser darauf geben so ahhh... for example when you... put water onto it, as she presses her thumb on the top of her notebook cover (Fig. 8a), dann then, she says as she points with a straight finger onto the cover (Fig. 8b), and then verbalized, vielleicht das maybe this, as she

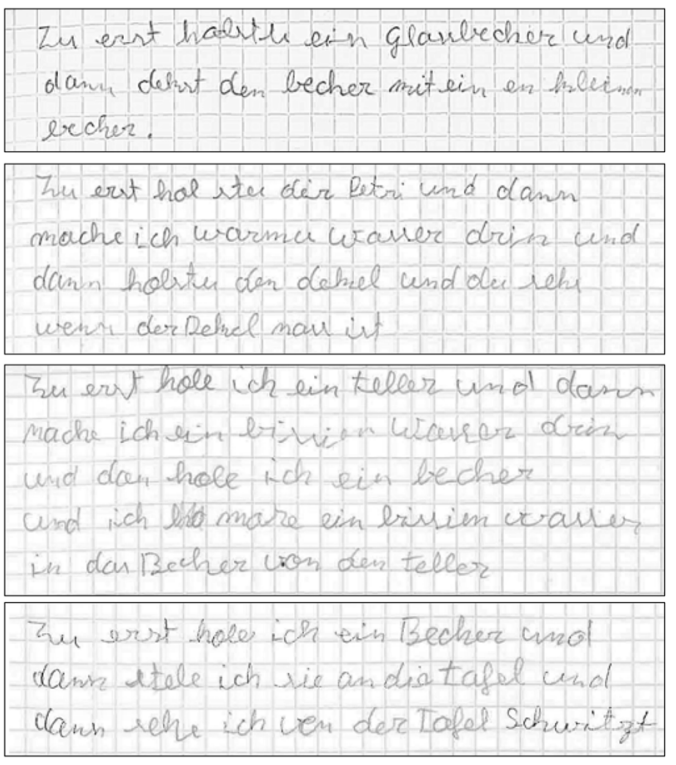

"First take a glass cup and then cover the cup with a small cup"

"First I take a Petri (dish) and then I put warm water in it and then take the lid and then you see when the lid is wet"

"First I take a plate and then I put a little water in it and then I take a cup and I put a little water in from the plate"

Fig. 6 Calia's four condensation investigation plans in her science notebook (in German)

"First I take a plate and then I set it on the board and then I see when the board sweats" 


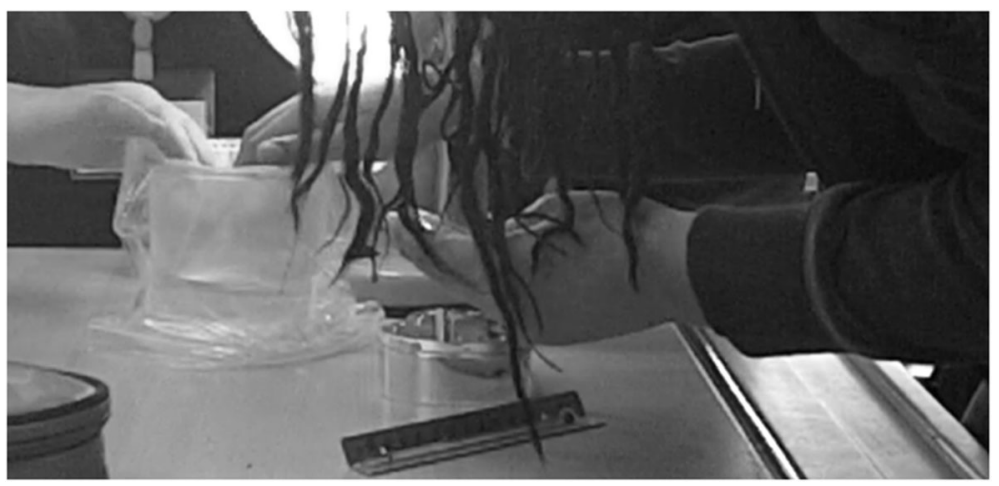

Fig. 7 Calia and her groupmate form a plastic cover over a beaker of water in order to observe condensation on day 3

pushes down to make a deep furrow in the notebook cover (Fig. 8c). In this portion of the episode, Calia demonstrates what she has observed in her prior investigations (Fig. 7) relative to what she had found out regarding condensation. She pushes her thumb down on to the top of her science journal and then points her straight finger on the cover of her notebook as she demonstrates and explains. Calia uses gestures as a central component of her explanation to Chris to indicate what she is thinking about the phenomena, a strategy common to language learners (Ünsal et al. 2018). Calia's verbal utterances in German "so, eh..." reinforce her search for expressive language which serve as filler phrases while she searches for descriptive words. Calia concludes her explanation in this excerpt with the general statement, "so maybe this". Calia's use of non-specific pronouns (e.g., "this") in the place of proper nouns to refer to specific phenomena coupled with gestures mirrors the findings of Roth and Lawless (2002) who illustrated how students' gestures arise in talk following student scientific investigations. Multimodal interaction analysis of this third episode reveals that Calia employs a combination of gestures and materials available to her (i.e., her notebook cover) and basic language to describe her thinking about the phenomena to Chris even though she does not have the expressive vocabulary in German (the language of instruction) to describe what she has observed. As such, and through fluid multimodal communication-in-situation, her understandings and wonderings become clearer through her discussion with Chris.

a

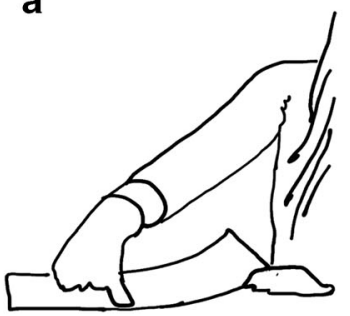

b

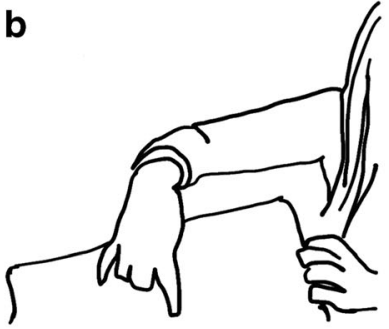

C

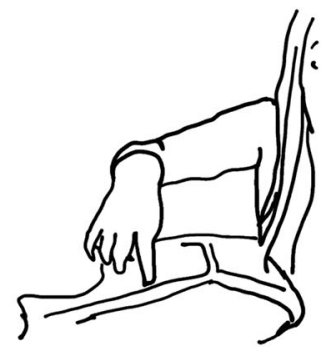

Fig. 8 Calia recreates the form of the indentation that led to condensation with her hand and her notebook cover on day 4 


\section{Discussion}

We have detailed a method for multimodal interaction analysis grounded in dialogic notions of embodied communication and interaction, and subsequently presented key episodes of Calia, a plurilingual student's engagement in inquiry science investigations. Through elaboration of the three episodes, we demonstrated how a process of MIA grounded in embodied utterances affords insight into Calia's use of semiotic resources in moment-to-moment interactions with peers and teachers in ways that might be obscured by analytical approaches grounded in verbal productions. This supports prior research findings that show how students' self-selection of combinations of modes (modal ensembles) provides multiple avenues for students to participate in science while working in languages they are also working to learn (e.g., Williams et al. 2019). The communicative complexities of this particular focal classroom are the perfect scenario for employing research methodologies such as MIA, which serve to decentralize the role of language and give more weight to additional multimodal communication resources that play a role in engagement in science. Calia drew on numerous semiotic and situational resources that were fluidly engaged, and analysis of Calia's participation in the condensation unit using MIA shows us how participation can be viewed in terms of embodied interaction with material-environment-people-semiotic resources in contextually oriented ways over time. A focus on multilingual students is a more recent development in the field of research in science education. Zooming in on Calia as a case allows for demonstrating the use of MIA because her linguistic profile exemplifies the language repertoires of many of the students in our national context, a complex language environment that has allowed us to refine this methodology. This builds from prior studies we have conducted that employ this methodology (Siry and Gorges 2019; Wilmes and Siry 2020) and that show the importance of considering all modes and semiotic resources visible within interaction. A key contribution of this analysis is that it reveals meaning-making and interaction through vocal, multimodal, and sociocultural understandings, which is key to deepening our research focus on diverse systems of meaningmaking through interaction, especially with plurilingual students. It can be argued however, that this is critical for all students, as the subjective use and development of language are not singular. Rather, we share the view that "all language users are - to a degree -'multilingual' but that no language user is - or can ever be - 'fully' competent" (Dufva et al. 2011, p.120). Through examining Calia as a case, we have sought to provide evidence for embodied engagement in science learning, and thereby the embodiment of communication and knowing (Roth 2009). In addition to providing resource-rich views of plurilingual students' science engagement, multilingual, multimodal practices can change power relations in classrooms and structure students' access to positions of expertise.

The analysis of the three illustrative episodes that we detailed shows how interaction with materials is just as key when students are investigating in the science classroom. The MIA analytical approach we propose honors these spaces of engagement mediated through interaction. When the complexities of science education framed as a lived practice are layered onto the linguistic complexities of classrooms in which children draw from diverse language and semiotic resources, analytic approaches that are rooted in the verbal create an overly simplistic representation that reduces CLD students' science understandings to semiotic modes of writing and speaking. Prioritizing the spoken and written aspects of science learning does not present the whole human complex of communication and engagement in science classrooms (Jaipal 2009). Analytic approaches grounded in viewing the entire contextualized semiotic 
environment, instead, reveal resources for interaction and meaning-making that can be obscured with methods grounded in the verbal.

The main contribution of this manuscript is the elaboration of a method of multimodal interaction analysis to examine students' embodied engagement in science, a method that is grounded in Bakhtinian notions of the lived, embodied utterance. This method does not seek to operationalize Bakhtinian conceptualizations into an exact analytical approach. It is an approach which has developed through our own dialogic conversation as researchers within the linguistic complexity of science instruction in our diverse national context, and with languagebased methods of analyzing student engagement. Methods grounded in language do not provide enough diffraction, in Bakhtinian terms, of the embodied material aspects of interactions. By this, we mean that there are aspects of engagement that are missed when speech and writing serve as the guiding frame for analysis. In our past research, meaningful components of plurilingual students' science engagement were overlooked, missed, and mis-judged when we performed analysis of dialog grounded in language-based theoretical perspectives. In conversation with this challenge, and as a dialogical response, we developed the MIA approach we elaborate here. Through the four steps we detail in prior sections, we aim to valorize the meaningful engagement of students we experience as we coteach in classrooms in our context.

As the field's perspectives on student diversity move and shift relative to new views of language drawn from sociolinguistic perspectives, we see a need for an equivalent shift in discourse analysis in ways that expand "the problem space for defining relevant aspects of interaction" (Kelly 2016 p.233). It is within this newly expanded problem space that we propose this method that allows us to view science education as an embodied discursive practice and to begin to address the methodological challenges faced by researchers who explore "how the lived experience of coming to know in science is embodied by speakers interacting with one another" (Kelly 2016 p.234). It is not our intent, with the methodology we suggest, to replace or supersede what scholarly work has been done to analyze discourse in science education. Our intent, rather, is to be inspired by dialogism and Bakhtinian thought to bring an additional methodological approach to the conversation about methodological plurality.

\section{Implications}

The methodologies we incorporate in our research have developed over time, driven by our focus on working towards resource-rich lenses (Siry 2011) for understanding the complexities of not just plurilingual students', but all students' interactions in science. Herein, we have drawn from understandings gleaned from across several studies to propose, illustrate, and elaborate the methodological implications of MIA grounded in dialogic theoretical perspectives for science education research specifically. There are implications of this work for research, instruction, and teacher professional development, as the claims shed light on the complexity and multiplicities of ways in which (plurilingual) children interact during openended science investigations in classroom contexts.

A multimodal perspective allows for paying attention to the wide range of resources drawn on in interaction, including gestures, gaze, body positioning, speech, tools, drawings, diagrams, and texts (Bezemer and Kress 2015). The analytical approach presented in this manuscript moves the use of MIA forward, in ways that support new perspectives on students' and teachers' interactions within the context of science instruction. This approach supports a conceptualization of science (education) as a practice that unfolds through interaction, versus a 
static collection of facts to be learned. Van Eijck and Roth (2011) built upon Bakhtin's analysis of epics and novels to suggest that science needs to be reframed from the notion of an epic, i.e., a grand narrative, and instead be positioned as a novel, as something that is shifting and changing and open to interpretation. In considering a suggested rise of the perspective of the novel, "Two myths perish simultaneously: The myth of a language that presumes to be the only language, and the myth of a language that presumes to be completely unified" (Bakhtin 1981, p. 68). This supports a perspective of science as novel, as shifting and open to interpretation and examination, and the implications for teaching practice support framing science learning beyond the learning of science concepts and processes - rather, by framing science learning as related to the fullness of life, and thus to the interconnected, multimodal ways students engage in science, with an understanding of the contextualized, relational ways in which this unfolds in practice.

The implications of this work also extend to teaching praxis, as framing teaching and learning as dialogic processes emphasizes the ever unfinished, incomplete, contextualized process of communication (Shields 2007 p. 155). This study emphasizes the value of working towards intentional use of spaces that support heteroglossia, Bakhtin's (1981) term for the coexistence of multiple often tension-filled voices, as it raises an awareness of connection between instructional spaces and students' access to semiotic resources (Bezemer and Kress 2019). A key contribution of the MIA methodology we elaborate here, and its grounding in Bakhtinian perspectives, is coming to understand diversity and difference, as something that is not to be celebrated, nor to overcome, but rather as something that simply is (Shields 2007). Recognizing and embracing this through the use of methodologies such as the one elaborated here can highlight the multiplicity of perspectives and experiences inherent in classrooms and, in doing so, recognize and valorize the heteroglossia that is inherent in human interactions. Working towards dialogicity in the classroom can open up the spaces for exchange around diversity, and the unfolding development of language and thought.

Funding This research was funded by the Luxembourg National Research Fund through an Aide à la Formation Recherche (AFR) Grant No. 4832121.

Data Availability The data associated with this study and analysis presented here is not publicly available.

\section{Compliance with Ethical Standards}

Conflict of Interest The authors declare that they have no conflict of interest.

Ethics Approval The research project detailed in this manuscript was granted research clearance through the University of Luxembourg's Ethics Review Board.

Consent to Participate The data sources drawn from this manuscript were obtained after consent to participate was given by all adults and parents of student participants, and assent to participate was provided by student participants.

Consent for Publication The data sources drawn from this manuscript were obtained after consent to participate was given by all adults and parents of student participants.

Open Access This article is licensed under a Creative Commons Attribution 4.0 International License, which permits use, sharing, adaptation, distribution and reproduction in any medium or format, as long as you give appropriate credit to the original author(s) and the source, provide a link to the Creative Commons licence, and indicate if changes were made. The images or other third party material in this article are included in the article's 
Creative Commons licence, unless indicated otherwise in a credit line to the material. If material is not included in the article's Creative Commons licence and your intended use is not permitted by statutory regulation or exceeds the permitted use, you will need to obtain permission directly from the copyright holder. To view a copy of this licence, visit http://creativecommons.org/licenses/by/4.0/.

\section{References}

Bakhtin, M. M. (1981). The dialogic imagination: four essays by M.M. Bakhtin (M. Holquist, Ed.; C. Emerson \& M. Holquist, trans.). Austin: University of Texas Press.

Bakhtin, M. M. (1984). Problems of Dostoevsky's poetics. Minneapolis: University of Minneapolis Press.

Bakhtin, M. M. (1986). Speech genres and other late essays [1953], trans. V. W. McGee, ed. C. Emerson and M. Holquist. Austin, TX: University of Texas Press.

Bezemer, J., \& Kress, G. (2015). Multimodality, learning and communication: a social semiotic frame. Routledge.

Bezemer, J., \& Kress, G. (2019). Semiotic work in the science classroom. Cultural Studies of Science Education, $15,1-4$.

Bostad, F., Brandist, C., Evensen, L. S., \& Faber, H. C. (Eds.). (2004). Bakhtinian perspectives on language and culture. Houndmills: Palgrave Macmillan.

Council of Europe (2018). Common European framework of reference for languages: learning, teaching, assessment. Companion volume with new descriptors. Strasbourg: Council of Europe. Available at https:// www.coe.int/en/web/common-european-framework-reference-languages

Dufva, H., Suni, M., Aro, M., \& Olli-Pekka, S. (2011). Languages as objects of learning: language learning as a case of multilingualism. Journal of Applied Language Studies, 1(5), 109-124.

Erickson, F. (2017). Conceiving, noticing, and transcribing multi-modality in the study of social interaction as a learning environment. Linguistics and Education, 41, 59-61. https://doi.org/10.1016/j.linged.2017.07.001.

Evensen, L. S. (2004). From dialogue to dialogism: The confessions of a writing researcher. In Bakhtinian perspectives on language and culture (pp. 147-164). Palgrave Macmillan, London. https://doi.org/10.1057/ 97802300056798.

Givry, D., \& Roth, W. M. (2006). Toward a new conception of conceptions: interplay of talk, gestures, and structures in the setting. Journal of Research in Science Teaching, 43(10), 1086-1109.

Holquist, M. (2004). Dialogism: Bakhtin and his world (2nd ed.). Routledge: New York.

Hwang, S., \& Roth, W. M. (2011a). The (embodied) performance of physics concepts in lectures. Research in Science Education, 41(4), 461-477.

Hwang, S., \& Roth, W. M. (2011b). Scientific \& mathematical bodies: The interface of culture and mind (Vol. 22). Springer Science \& Business Media.

Jaipal, K. (2009). Meaning making through multiple modalities in a biology classroom: a multimodal semiotics discourse analysis. Science Education, 94(1), 48-72.

Jewitt, C., Bezemer, J., \& O'Halloran, K. (2016). Introducing multimodality. New York: Routledge.

Kelly, G. J. (2016). Learning science: Discourse practices. In: S. Wortham, D. Kim, and S. May (Eds.), Discourse and education. Encyclopedia of language and education (3rd ed.), 223-237. Cham; Springer. https://doi.org/10.1007/978-3-319-02322-9_29-1.

Konicek-Moran, R. (2008). Everyday science mysteries: stories for inquiry-based science teaching. Arlington: NSTA Press.

Kontra, C., Goldin-Meadow, S., \& Bellock, S. (2012). Embodied learning across the lifespan. Topics in Cognitive Science, 4, 731-739.

Kress, G. R. (2010). Multimodality: a social semiotic approach to contemporary communication. New York: Routledge.

Kress, G., Jewitt, C. O., Ogborn, J. J., \& Tsatsarelis, C. (2001). Multimodal teaching and learning. The rhetorics of the science classroom. New York: Continuum.

Lemke, J. L. (2004). The literacies of science. Crossing borders in literacy and science instruction: perspectives on theory and practice, 33-47.

Lotman, J. (1977). Structure of the artistic text (Ronald Vroon, Trans.). Ann Arbor: Ardis Publishers.

Márquez, C., Izquierdo, M., \& Espinet, M. (2006). Multimodal science teachers' discourse in modeling. Science Education, 90(2), 202-226. https://doi.org/10.1002/sce.20100.

MENJE. (2019). Les chiffres clés de l'éducation nationale: Statistiques et indicateurs 2017/2018 (Key numbers of national education: statistics and indicators 2017/2018). Luxembourg. 
Moro, L., Mortimer, E. F., \& Tiberghien, A. (2019). The use of social semiotics multimodality and joint action theory to describe teaching practices: two cases studies with experienced teachers. Classroom Discourse, 11, $1-23$.

National Research Council (NRC). (2012). A framework for K-12 science education: practices, crosscutting concepts, and core ideas. Washington, DC: National Academies Press. https://doi.org/10.17226/13165

NGSS Lead States. (2013). Next generation science standards: for states, by states. https://oi.org/10.1007/ s13398-014-0173-7.2

Norris, S. (2004). Analyzing multimodal interaction: a methodological framework. London: Routledge.

Norris, S. (Ed.). (2012). Multimodality in Practice: Investigating Theory-in-practice-throughmethodology (Vol. 4). Routledge. https://doi.org/10.4324/9780203801246

Norris, S. (2020). Multimodal interaction analysis. In C. A. Chapelle (Ed.), The concise encyclopedia of applied linguistics. Malden: Wiley.

Norris, S., \& Pirini, J. P. (2017). Communicating knowledge, getting attention, and negotiating disagreement via videoconferencing technology: a multimodal analysis. Journal of Organizational Knowledge Communication, 3(1), 23-48.

Otrel-Cass, K., \& Kristensen, L. K. (2017). Troubling an embodied pedagogy in science education. In Ethnography and Education (pp. 69-91). London: Tufnell Press.

Pappas, C. C., Varelas, M., Barry, A., \& Rife, A. (2002). Dialogic inquiry around information texts: The role of intertextuality in constructing scientific understandings in urban primary classrooms. Linguistics and Education, 13(4), 435-482. https://doi.org/10.1016/s0898-5898(03)00004-4.

Pirini, J., Matelau-Doherty, T., \& Norris, S. (2018). Multimodal analysis. In A. Phakiti, P. De Costa, L. Plonsky, \& S. Starfield (Eds.), The Palgrave handbook of applied linguistics research methodology (pp. 639-658). London: Palgrave Macmillan.

Roth, W. M. (2005). Talking science: language and learning in science classrooms. Lanham: Rowman \& Littlefield Publishers.

Roth, W. M. (2009). Dialogism: a Bakhtinian perspective on science and learning. Leiden: Brill Sense.

Roth, W. M., \& Lawless, D. (2002). Scientific investigations, metaphorical gestures, and the emergence of abstract scientific concepts. Learning and Instruction, 12(3), 285-304.

Roth, W. M., \& Tobin, K. (2004). Coteaching: from praxis to theory. Teachers and Teaching, 10(2), 161-179.

Rule, P. (2011). Bakhtin and Freire: dialogue, dialectic and boundary learning. Educational Philosophy and Theory, 43(9), 924-942.

Salloum, S., \& BouJaoude, S. (2019). The use of triadic dialogue in the science classroom: a teacher negotiating conceptual learning with teaching to the test. Research in Science Education, 49(3), 829-857.

Shields, C. (2007). Bakhtin primer. New York: Peter Lang.

Siry, C. (2011). Exploring the significance of resource-rich views in science education. Cultural Studies of Science Education, 6(4):1019-1029. https://doi.org/10.1007/s11422-011-9353-3.

Siry, C. (2013). Exploring the complexities of children's inquiries in science: Knowledge production through participatory practices. Research in Science Education, 43(6), 2407-2430. https://doi.org/10.1007/s11165013-9364-z.

Siry, C., \& Gorges, A. (2019). Young students' diverse resources for meaning making in science: learning from multilingual contexts. International Journal of Science Education, 1-23. https://doi.org/10.1080/09500693. 2019.1625495.

Siry, C., Ziegler, G., \& Max, C. (2012). "Doing science” through discourse-in-interaction: Young children's science investigations at the early childhood level. Science Education, 96(2), 311-326. https://doi.org/10. 1002/sce.20481.

Ünsal, Z., Jakobson, B., Wickman, P. O., \& Molander, B. O. (2018). Gesticulating science: Emergent bilingual students' use of gestures. Journal of Research in Science Teaching, 55(1), 121-144. https://doi.org/10.1002/ tea. 21415.

van Eijck, M., \& Roth, W. M. (2011). Cultural diversity in science education through novelization: against the epicization of science and cultural centralization. Journal of Research in Science Teaching, 48(7), 824-847.

Varelas, M., \& Pappas, C. C. (Eds.). (2013). Children's ways with science and literacy: integrated multimodal enactments in urban elementary classrooms. Abingdon: Routledge.

Wertsch, J. V. (1998). Mind as action. Oxford: Oxford university press.

Williams, M., \& Tang, K. S. (2020). The implications of the non-linguistic modes of meaning for language learners in science: a review. International Journal of Science Education, 42, 1-27.

Williams, M., Tang, K. S., \& Won, M. (2019). ELL's science meaning making in multimodal inquiry: a casestudy in a Hong Kong bilingual school. Asia-Pacific Science Education, 5(1), 3.

Wilmes, S. E. D. (2017). Student-driven inquiry-based science education in Luxmbourg primary school contexts. (Doctoral dissertation). University of Luxembourg. Retrieved from http://hdl.handle.net/10993/32187. 
Wilmes, S. E. D., \& Siry, C. (2018). Interaction rituals and inquiry-based science instruction: Analysis of student participation in small-group investigations in a multilingual classroom. Science Education, 102(5), 11071128. https://doi.org/10.1002/sce.21462.

Wilmes, S. E. D., \& Siry, C. (2020). Science notebooks as interactional spaces in a multilingual classroom: Not just ideas on paper. Journal of Research in Science Teaching, 57(7), 999-1027. https://doi.org/10.1002/tea. 21615.

Wilmes, S. E. D., Siry, C., Gómez Fernández, R., \& Gorges, A. (2018). Reconstructing science education within the language | science relationship: Reflections from multilingual contexts. In L. A. Bryan \& K. Tobin (Eds.), 13 Questions. Reframing education's conversation: Science (pp. 251-266). New York: Peter Lang.

Zhang, Y. (2016). Multimodal teacher input and science learning in a middle school sheltered classroom. Journal of Research in Science Teaching, 53(1), 7-30.

Publisher's Note Springer Nature remains neutral with regard to jurisdictional claims in published maps and institutional affiliations. 